\title{
American Pediatric Society's 2007 John Howland Award Acceptance Lecture
}

\author{
RALPH D. FEIGIN \\ Department of Pediatrics, Texas Children's Hospital, Baylor College of Medicine, Houston, TX 77030
}

$\mathrm{P}^{\mathrm{s}}$ resident McCabe, Members of the Pediatric Academic Societies and Guests, Family and Friends:

Words cannot convey adequately how overwhelmed I felt when Ed McCabe informed me that I had been chosen to receive the John Howland Award. I am deeply appreciative to the American Pediatric Society, its Council, and the entire membership for honoring me in this manner. I would like to convey my deep gratitude to Gail Demmler for her overly gracious presentation. I had been nominated initially by Dr. Norm Seigel who died while attending this meeting last year. I worked with Norm over many years as a member of the Councils of the SPR and APS. I have the deepest respect and admiration for Norm and for everything that he accomplished and miss him enormously.

It has been a wonderful tradition for the Howland awardees to speak about those individuals who have significantly influenced their life.

Many have contributed to mine, but none more than my wife, Judy. Judy and I were married at the end of my second year of medical school and after her graduation from college. We will be celebrating our $47^{\text {th }}$ anniversary in June. Nothing that I may have accomplished would have been possible without her love, support, and encouragement. Our children and grandchildren have been an enormous source of pride and pleasure to both of us. They have our love, respect, and admiration.

The 1994 Howland awardee, Dr. Sydney S. Gellis, (Fig. 1A) was the person who first attracted me to pediatrics. Dr. Gellis' charisma as a clinician and teacher was such that within two weeks of beginning a core pediatric rotation, I was hooked for life. Sydney was an outstanding mentor and life-long friend until his death and was the consummate role model as a clinician and teacher.

For my third year of residency training, Sydney encouraged me to go to the Massachusetts General Hospital, which I did. It was there that I met Dr. Philip R. Dodge, whom I will return to in a moment.

A two-year hiatus, however, ensued, courtesy of the United States Army and the outbreak of the war in Viet Nam. This unanticipated deviation in career path taught me much about

Received May 16, 2007; accepted May 20, 2007.

Ralph D. Feigin, M.D., Baylor College of Medicine, Texas Children's Hospital, Department of Pediatrics, Chairman, One Baylor Plaza, MS BCM320, Houston, TX 77030; e-mail: rfeigin@bcm.edu

Presented at the 2007 Annual Meeting of the Pediatric Academic Societies, Toronto, Ontario, Canada.

Supplemental material available online at www.pedresearch.org serendipity and its role in shaping one's career. I was assigned to the United States Medical Army Research Institute of Infectious Diseases at Ft. Detrick in Frederick, Maryland. I was given top secret clearance to work on defensive aspects of biologic warfare. It was during this sojourn that I met several individuals who were so important to the evolution of my career, namely: Dr. William R. Beisel and members of the Armed Forces Epidemiology Board (Drs. Ted Woodward, Lee Cluff, Thomas Francis, Charles Rammelkamp, Vernon Knight, and Albert Sabin - another former Howland awardee), the members of this Board to whom we reported. They gave me much guidance and advice.

I returned to Boston and Harvard Medical School as I had promised, but during the time I had been in the service Phil Dodge (Fig. 1B) accepted a position as Chair of the Department of Pediatrics at Washington University School of Medicine. Phil enticed me to leave after a year and join him in St. Louis in 1968.

Those were wonderful years where I had the opportunity to work with many students, residents, and fellows who today are leaders of pediatrics and of academic institutions nationally. Phil permitted me the freedom to build the clinical and laboratory-based infectious disease program and supported my endeavors in every way possible. He collaborated with me on many prospective studies of bacterial meningitis where we followed patients for a period of 25 years, even after I left St. Louis.

It was in St. Louis that I began to work with other collaborators who have been extremely important and so meaningful in my career. James Cherry (Fig. 1C) was Chief of Infectious Diseases at St. Louis University School of Medicine at the time I was in St. Louis. We evaluated, together with our fellows, the pharmacokinetics of cefazolin before its approval by the FDA, and established both its safety and efficacy for treating infectious diseases of children. We performed similar studies on the safety and efficacy of Clindamycin that led to its approval for use in children. We investigated several outbreaks of measles virus infection in the St. Louis community and documented the need for a second dose of MMR more than 12 years before the recommendation finally was implemented by the Centers for Disease Control. Jim has been a life-long colleague and friend. I am indebted to him for working with me so many years as co-editor and co-author of the Textbook of Pediatric Infectious Diseases, now with its sixth edition in press. We were joined by Sheldon Kaplan and Gail Demmler in the fifth edition and in the sixth edition. We are all indebted to many in this audience who have authored chapters in these texts. I must interject a word here about another former Howland awardee, Dr. 


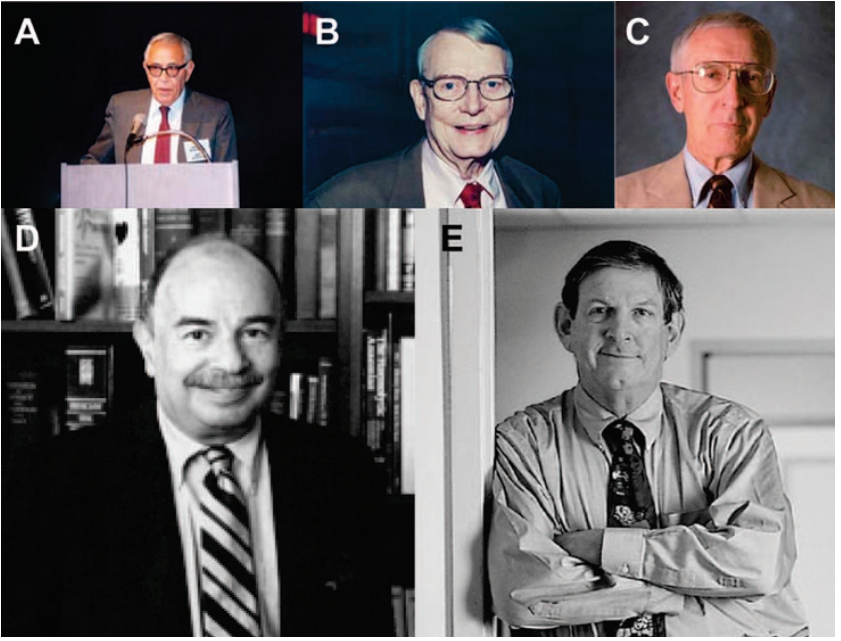

Figure 1. (A) Dr. Sidney S. Gellis, the consummate clinician and educator. $(B)$. Dr. Philip R. Dodge, Chair Emeritus, Department of Pediatrics, Washington University School of Medicine; Dr. Feigin's chief when Dr. Feigin was Head of the Division of Pediatric Infectious Diseases at Washington University School of Medicine. (C) Dr. James D. Cherry, currently Chief of Infectious Diseases, Department of Pediatrics, University of California School of Medicine at Los Angeles, and long-time collaborator with Dr. Feigin. $(D)$ Dr. Frank Oski, premier clinician, teacher, and editor. $(E)$ Dr. Joseph Warshaw, pediatrician and developmental biologist; one of the founders of the Pediatric Scientist Development Program.

Sam Katz. For reasons unknown to me, Sam contacted me during the year after I returned from military service, asking me to join him in one of the studies of rubella vaccine that he was conducting and has served as a mentor and life-long friend ever since.

Two other individuals who had a great influence on my life were both international leaders of the pediatric community who left us prematurely, namely, Drs. Frank Oski and Joseph Warshaw. Both, in my opinion, would have been Howland awardees, and it is a personal privilege for me to recognize them and honor them today (Fig. 1D). Frank's studies in the field of hematology and iron metabolism are known by all in this audience. His skills as a clinician and a teacher were unsurpassed. Frank was a mentor, a visionary, a scientist, and a clinician, but, above all, he was a teacher. He served as chair of two pediatric departments - the State University of New York in Syracuse and subsequently Johns Hopkins University School of Medicine. I was honored when he asked me to join him to editor Principles and Practice of Pediatrics, now in its fourth edition known as Oski's Pediatrics.

Joe Warshaw (Fig. 1E) and I met at the Massachusetts General Hospital when he was a fellow in endocrinology and metabolism. Joe's work in developmental biology and his career as Chair of Pediatrics at Dallas Southwestern Medical School and then at Yale University, and finally as Dean of the University of Vermont School of Medicine are equally well known. Joe was larger than life itself. He loved life and lived it fully while achieving excellence as a physician, scientist, educator, and mentor. Joe helped found the Pediatric Scientist Development Program. Joe joined Frank, myself, and Cathy DeAngelis in the initial editions as co-editors of Principles and Practice of Pediatrics. Frank and Joe, thank you for all that you have contributed to my life and to that of so many others.
I was equally honored to have worked with Julia McMillan, who took over for Frank as senior editor of the text during Frank's illness and subsequent to his death, and Cathy DeAngelis who has collaborated with us on all four editions, as well as Doug Jones who took over for Joe Warshaw midway through the preparation of the fourth edition of the book.

It must be apparent to you that the first major decision of my medical career was to pursue an academic pediatric career.

My next and most important major decision was that of agreeing to chair a pediatric department. This was for me an opportunity to help mold, nurture, and develop the environment that would support optimal clinical care, research, and community-based initiatives. My joy in this job has been enormous, and has been derived significantly from the successes of our extended family in this endeavor. Over the years, I have been blessed with fantastic students, residents, fellows, and faculty. It is easy to refer to those who have become section heads, chairs, and deans of medical schools by name, but I would really like to recognize all of them - the more than 1,500 trainees who have taken leadership positions, not only in academic settings but those on the firing line in the practice of pediatrics. They all share in this occasion. All of them, past and present, have helped generate the excitement that makes pediatrics both rewarding and enjoyable. I am especially grateful to my colleagues in my own department at Baylor College of Medicine and Texas Children's Hospital whom I admire and respect beyond words (Figure S1, online). This award is as much a recognition of them and their accomplishments as it is of my own.

I also would like to thank Jerry Lucey who asked me to join him first as a Consulting Editor and then as an Associate Editor for Pediatrics. Jerry has been the consummate editor and from him I have learned much during the course of my career.

I began my career focused on developing methods to determine the nature of the microorganisms producing disease following intentional dissemination by bioterrorists before the time that they produced clinical disease. Little did I know that a virtual lifetime later, bioterrorism would be a greater real threat to our own population and that of others around the world than it was in 1965.

We should recognize, however, that infectious diseases, which occur as natural events, pose the greater ever present threat to mankind. Infections continue to emerge or re-emerge that have the capacity to sicken or kill millions of people worldwide. (Table 1) The World Health Organization has recognized more than 30 new infectious diseases since 1980. In addition, historically established infectious diseases, such as Monkey Pox, West Nile, tuberculosis, and malaria have re-emerged or resurged, sometimes in populations that previously had been exempt from such affront. Strains of common microbes such as Staphylococcus aureus have continued to develop resistance to drugs that were once effective against them and even to have developed increased virulence for the normal host. Infectious diseases are still the third leading cause of death in the United States and the second leading cause of death on a worldwide basis.

I would suggest that our approach to these problems must change markedly and immediately. 
Table 1. Newly recognized as emerging infectious diseases (1980-2006)

Tuberculosis Malaria
HIV (AIDS)
Methicillin-resistant S. aureus
West Nile
Monkey Pox
Lassa Fever
Rift Valley Fever
Hantavirus (Sin Nombre)
Hantavirus (Seoul)
Hantavirus (Prospect Hill)
Cholera (V. cholera 0139 )
Bolivian Hemorrhagic Fever
(Machupo Virus)
Yellow Fever
Venezuelan equine encephalomyelitis
Dengue (Australia)
Anthrax
Plague (India)
Morbillivirus
Metapneumoviruses
Hendra
Nipah
Severe acute respiratory distress associated coronavirus (SARS)

Two parallel courses of action are required. The first is a scientific and research direction which must be focused on improving our methods of diagnosing and treating both old and new infectious diseases (1). Expression profiling using microassays permits the study of the regulatory response of both the pathogen and the host during infectious illness. These techniques should be deployed worldwide and should help to identify the new causal agents of both acute infection and chronic disease. Parallel studies soon will permit simultaneous screening for microbial pathogens and for genetic determinants of inflammation and host susceptibilities to infection. The confluence of genetics and molecular diagnostics for application to infectious diseases offers the promise of treatment or preventive strategies that can even be individualized for each patient. The emergence of real time DNA sequencing and pyro-sequencing is enabling clinical laboratories to consider sequenced-based pathogen identification for the first time.

I believe that these parallel molecular techniques will be superior to our currently used microbial culture-based strategies, since they could screen for different pathogens without being limited by being able to only identify viable or culturable organisms.

Specific research to treat or prevent diseases such as tuberculosis, malaria and HIV must be further accelerated. Between 300 million and 500 million new cases of malaria occur annually with 1-3 million deaths and the deaths are predominately in children.

To combat problems such as the marked increase in local and invasive infection due to community-acquired methicillinresistant Staphylococcus aureus and other similar organisms, future research must be focused on understanding bacterial virulence factors and on developing methods to enhance host immunity or to block receptor sites by which these and other organisms establish colonization before invasion. Microbial virulence factors may be used to produce immunotherapeutic
Table 2. Questions to be addressed by international community to implement procedures to delete emerging microbial diseases at their inception

What are the most effective means of containing new infectious diseases? What are the acceptable limits of government control?

What social costs are we willing to pay to respond with the vigilance required?

Do we need more disease detection at airports or tougher quarantine laws? What might the ripple effect on the economy be?

Can we develop detection systems using molecular signature methodology?

compounds that will support conventional therapy. High throughput methods of identifying genes essential for the growth of pathogens will lead to identification of new classes of antimicrobial drugs that can affect novel targets. I would hope that some of you in this audience with an interest in research in infectious diseases would pursue some of these avenues as your careers evolve.

The second approach is a much more global one. We will be required to accept a much more global perspective than we have in the past. We have historically been a country that has been somewhat neglectful of the microbes. Both in America and in other parts of the world, this recurring theme is coming back to haunt us. While the human race battles itself in many parts of the world today, fighting over ethnic issues, territory, or over increasingly crowded turf and scarcer resources, the advantage is, in fact, moving to the microbes court. The microbes are our predators and they will be victorious if we, the human race, do not learn to live in a rational global village that affords the microbes fewer opportunities or which at least gives us the opportunity, without geographical and political constraints, to detect the emerging microbial diseases at their inception utilizing some of the new techniques previously described to diagnose, contain and treat these disorders before epidemics are established. This will require much international cooperation devoted toward this common goal and answers to some difficult questions such as those shown on this slide (Table 2):

Members of these pediatric societies have always sought solutions to problems that had a marked effect on morbidity and mortality worldwide.

We have a renewed opportunity today to recognize the need to attack infectious disease problems on a global scale and we must resolve to do so. Programs such as the Baylor International Pediatric AIDS Initiative established by Dr. Mark Kline, with clinics that serve to care for children and through which research can be conducted in sub-Saharan Africa and other parts the world, are a wonderful example of what can be done (Figure S2, online). It is my profound hope that in our research and planning efforts we do our best to impact infectious diseases and other child health problems globally to ensure that our children and grandchildren can enjoy a life expectancy at least as long, or longer than those achieved by the current generation.

In closing, I would like to thank you again for giving me this greatest honor of my life. Each of you has my greatest admiration, respect, and profound thanks.

\section{REFERENCE}

1. Feigin RD 2005 Prospects for the future of child health through research. JAMA 294:1373-1379 